\title{
An efficient total synthesis of the pyrroquinazolinoquinoline alkaloid Luotonin A, employing an intramolecular hetero Diels-Alder reaction
}

\author{
Masahiro Toyota,* Chiyo Komori, and Masataka Ihara* \\ Department of Organic Chemistry, Graduate School of Pharmaceutical Sciences, Tohoku \\ University, Aobayama, Sendai 980-8578, Japan \\ E-mail:mihara@mail.pharm.tohoku.ac.jp
}

Dedicated to Professor Keiichiro Fukumoto on his $70^{\text {th }}$ birthday

(received 24 Jan 03; accepted 28 Apr 03; published on the web 02 May 03)

\begin{abstract}
The intramolecular hetero- Diels-Alder reaction of an aryl imino ether (diene) with an aryl nitrile (dienophile) has been used as the key reaction in an efficient approach to the pyrroquinazolino-quinoline alkaloid, luotonin A. Activation of the diene moiety by the incorporation of a methoxy group played an important role for the hetero Diels-Alder reaction.
\end{abstract}

Keywords: Alkaloid, Luotonin A, hetero Diels-Alder, pyrroquinazolinoquinoline, aryl imino ether, aryl nitrile

\section{Introduction}

The rapid synthesis of complex polycyclic molecules is a continuing challenge for organic chemists. One of the most powerful methodologies for the construction of such molecules uses the Diels-Alder reaction. Since its inception in 1928, the Diels-Alder reaction has been widely used for the synthesis of a myriad of bioactive natural products. ${ }^{1}$ With the potential of forming not only carbon-carbon bonds but also carbon-heteroatom bonds, this protocol has also been applied to the efficient construction of heterocycle-containing natural products. Since heterocycles comprise the 
core of various types of bioactive natural products, hetero Diels-Alder reactions, in which either the diene or dienophile may contain one or more heteroatoms, have been extensively studied. ${ }^{2}$

We have been especially interested in the reactivity of the acetylene moiety (as a dienophile) in thermal Diels-Alder reactions. ${ }^{3}$ In the course of our synthetic study of mappicine, we observed that the aryl-acetylene $\mathbf{2}$, generated from amide $\mathbf{1}$ in the presence of TMSCl, $i-\mathrm{Pr}_{2} \mathrm{NEt}$ and $\mathrm{ZnCl}_{2}$, provided the cycloadduct 3 in 76\% yield under thermal reaction conditions (Scheme 1). ${ }^{4}$

Although the ability of a nitrile to act as a dienophile in the Diels-Alder reaction has been disclosed by Dilthey and his coworkers, ${ }^{5}$ the applicability of such systems has been little explored. Here we present a three-step synthesis of luotonin A (4) using the hetero Diels-Alder reaction of an aryl nitrile and a 1-azadiene.

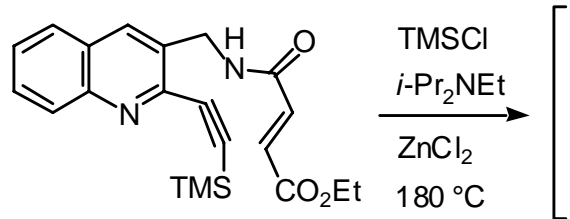

1<smiles>CCOC(=O)C=CC(=NCc1cc2ccccc2nc1C#CCS)O[Na]</smiles>

2

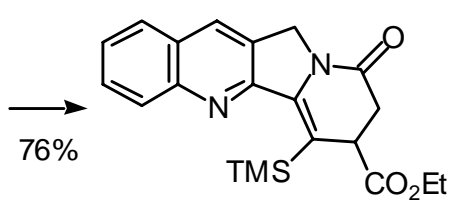

3

\section{Scheme 1}

\section{Retrosynthetic analysis}

Luotonin A (4) was isolated in 1997 from Peganum nigallastrum by Nomura and his coworkers. ${ }^{6}$

Owing to its unique structural features and biological activity, luotonin A (4) has attracted considerable attention from organic chemists. ${ }^{7}$

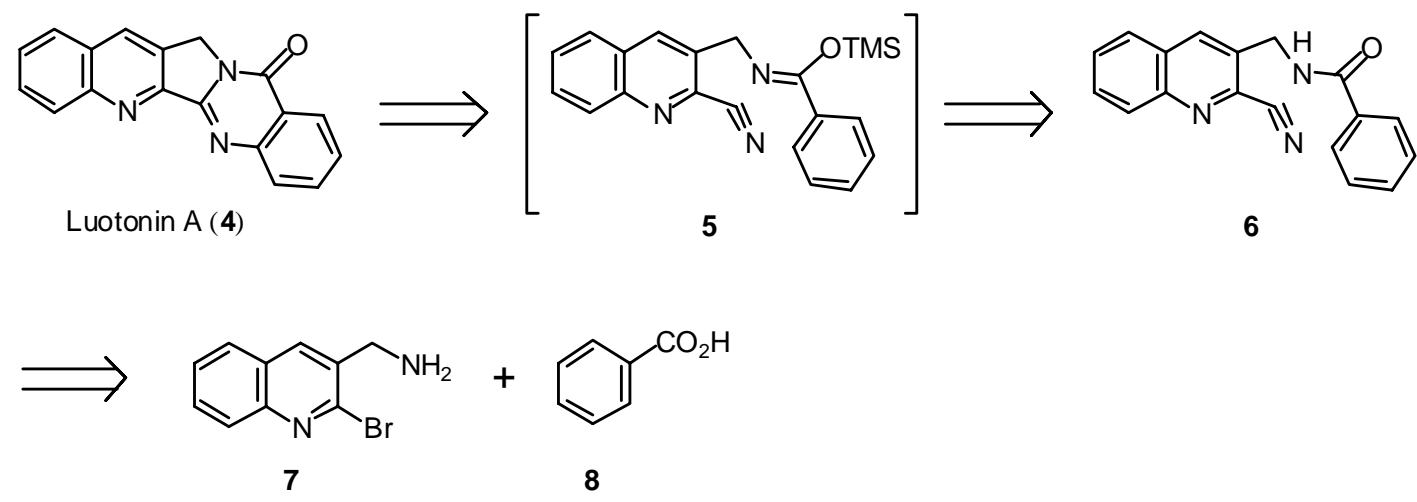

\section{Scheme 2}


Our retrosynthetic analysis for luotonin A (4) is shown in Scheme 2. The intramolecular hetero Diels-Alder reaction of the aryl imino ether 5, obtainable in situ from the amide $\mathbf{6}$, followed by autoxidation, was expected to provide luotonin A (4). The amide 6 should be prepared easily by condensation of the amine $\mathbf{7}$ and benzoic acid $\mathbf{8}$.

\section{Results and Discussion}

In practice, 3-(aminomethyl)-2-bromoquinoline (7) ${ }^{8}$ was coupled with benzoic acid (8) in the presence of benzotriazol-1-yloxy-tris(dimethylamino)phosphonium hexafluoro-phosphate (BOP) to afford the amide 9 in $92 \%$ yield. Introduction of the cyano group at the C-2 position of the bromide 7 was next performed using Sakamoto and Ohsawa's protocol, ${ }^{9}$ and the desired cyanide 10 was obtained in 97\% yield. After installation of the dienophile part, the amide $\mathbf{1 0}$ was subjected to intramolecular hetero Diels-Alder reaction. However, most of the starting material 10 was recovered unchanged and only small account of an unidentifiable compound was formed (Scheme 3).

It is known that both intra- and intermolecular hetero Diels-Alder reactions with alkyl- and aryl nitriles as the heterodienophiles require very high reaction temperatures. ${ }^{10}$ To overcome this drawback, a considerable number of investigations have been made. For example, sulfonyl cyanides and cyanoformates, bearing strong electron-withdrawing groups, have been used as practical dienophiles for intermolecular Diels-Alder reactions. ${ }^{11}$ However, there is still plenty of room for improvement.
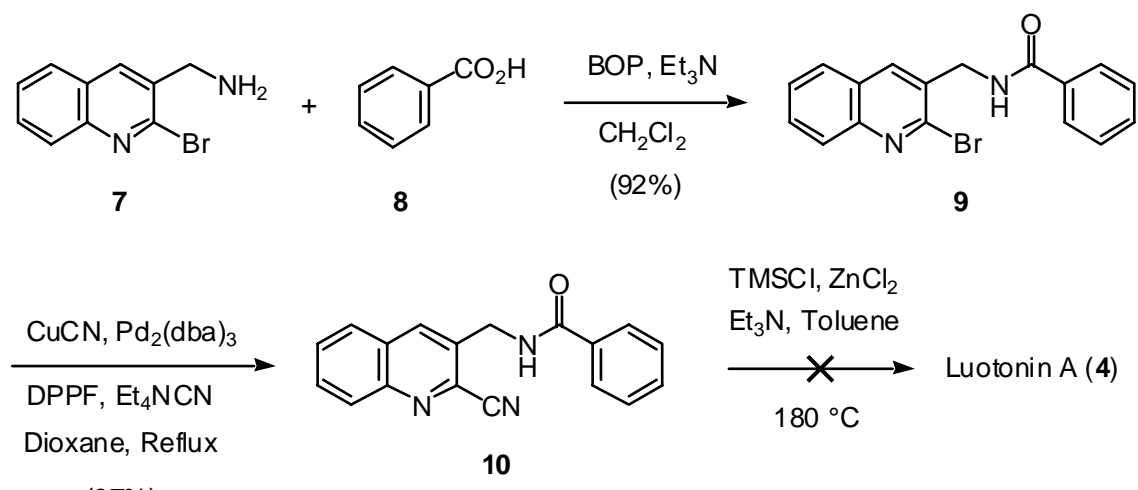

$(97 \%)$ 


\section{Scheme 3}

In order to solve our own problem, we decided to introduce an electron-donating substituent into a diene unit to increase the HOMO energy. In addition, we expected that methanol could be easily eliminated after cyclization (B) to recover the aromaticity of the benzene ring (C), and so a methoxy group was adopted as the substituent in the diene moiety (A) (Scheme 4).

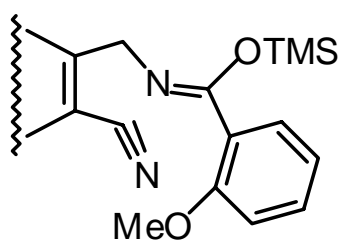

A

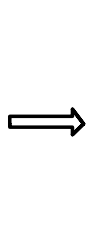

A
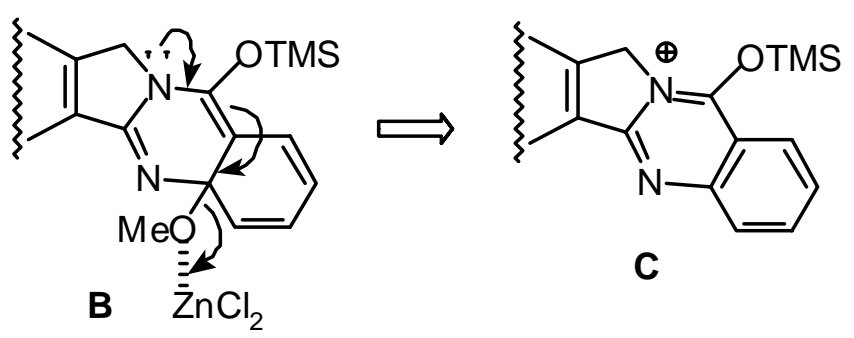

\section{Scheme 4}

The requisite substrate $\mathbf{1 3}$ for the hetero Diels-Alder reaction was prepared by a method similar to that described above (Scheme 5). The cyanide 13 was synthesized through condensation of the amine 7 and 2-methoxybenzoic acid (11) in the presence of BOP. Introduction of a cyano group into 12 gave rise to the amide 13 in 84\% yield. With the compound 13 in hand, it was subjected to the key intramolecular hetero Diels-Alder reaction. Heating of $\mathbf{1 3}$ with TMSCl and $\mathrm{Et}_{3} \mathrm{~N}$ at $150{ }^{\circ} \mathrm{C}$ in toluene in a stainless sealed tube in the presence of $\mathrm{ZnCl}_{2}$ produced luotonin $\mathrm{A}$ (4) in $46 \%$ yield. The synthetic 4 thus obtained was spectroscopically identical with that reported. $^{6 a}$
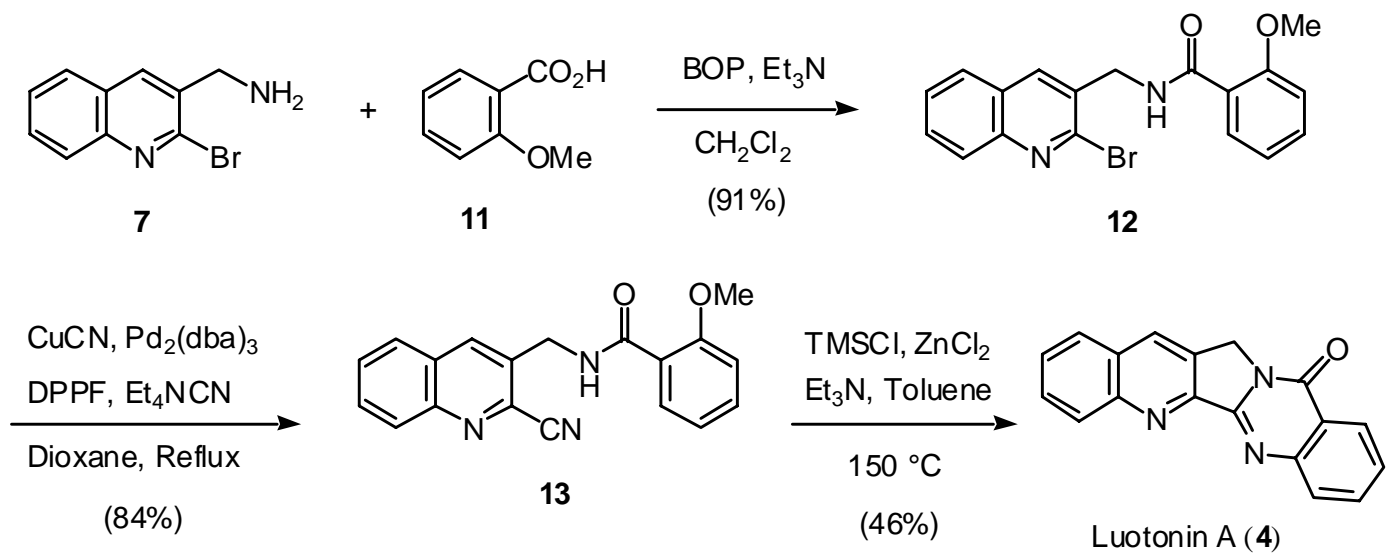


\section{Scheme 5}

\section{Conclusions}

We have accomplished an efficient total synthesis of pyrroquinazolinoquinoline alkaloid, luotonin A (4). Key to the development of the concise strategy delineated is the intramolecular hetero Diels-Alder reaction of aryl imino ether with aryl nitrile. This procedure would also be useful for the preparation of rutaecarpine.

\section{Experimental Section}

General Procedures. Unless otherwise noted, all reactions were performed in oven-dried glassware, sealed with a rubber septum under an atmosphere of argon. Anhydrous THF and $\mathrm{CH}_{2} \mathrm{Cl}_{2}$ were purchased from Kanto Chemical Co., Inc. Toluene and 1,4-dioxane were distilled from $\mathrm{CaH}_{2}$ prior to use. $\mathrm{Et}_{3} \mathrm{~N}$ was distilled from $\mathrm{KOH}$ immediately before use. Hexane, EtOAc and $\mathrm{CHCl}_{3}$ were distilled prior to use. Unless otherwise mentioned, materials were obtained from commercial suppliers and used without further purification. Organic extracts were dried by stirring over anhydrous $\mathrm{Na}_{2} \mathrm{SO}_{4}$ or $\mathrm{MgSO}_{4}$, filtered through Celite and concentrated under reduced pressure with the aid of a rotary evaporator. Flash chromatography was carried out using Merck 60 (230-400 mesh) or Cica 60 (spherical, 40-100 $\mu \mathrm{m}$ ) silica gel. Reactions and chromatography fractions were analyzed employing precoated silica gel $60 \mathrm{~F}_{254}$ plates (Merck). Compounds were visualized using an ultraviolet lamp (254 nm) and/or by staining with $p$-anisaldehyde (in EtOH), phosphomolybdic acid (in EtOH), or ammonium molybdate (in $10 \% \mathrm{H}_{2} \mathrm{SO}_{4}$ ). IR spectra were measured on a FT-IR 8300 spectrophotometer or a JASCO IR-report 100 spectrophotometer. NMR spectra were recorded on a Varian Gemini 2000 spectrometer with tetramethylsilane as an internal standard. Mass spectra were recorded on JEOL JMS-DX-303 or JMS-AX-500 spectrometers. All melting points were determined on Yanaco micro melting point apparatus and were uncorrected. 
N-(2-Bromoquinolin-3-ylmethyl)benzamide (9). To a stirred solution of the amine 7 (300 mg, $1.27 \mathrm{mmol}$ ) and benzoic acid (8) (155 mg, $1.27 \mathrm{mmol}$ ) in $\mathrm{CH}_{2} \mathrm{Cl}_{2}$ (13 mL) were added BOP (562 $\mathrm{mg}, 1.27 \mathrm{mmol})$ and $\mathrm{Et}_{3} \mathrm{~N}(0.35 \mathrm{~mL}, 2.54 \mathrm{mmol})$ at room temperature, and then the mixture was stirred at the same temperature for $30 \mathrm{~min}$. After removal of the solvent under reduced pressure, the crude product was chromatographed. Elution with a 2:1 mixture of hexane-EtOAc afforded the amide 9 (395 mg, 92\%) as white crystals, m.p. $137{ }^{\circ} \mathrm{C}$. IR (KBr): 3292, $1634 \mathrm{~cm}^{-1} .{ }^{1} \mathrm{H}$ NMR (300 MHz, $\mathrm{CDCl}_{3}$ ) $\delta, 4.85$ (2H, d, J=7.0 Hz), 6.95 (1H, br. s), 7.45-7.60 (4H, m), 7.75 (1H, ddd, $J=9.0,7.0,1.5 \mathrm{~Hz}), 7.80-7.83(3 \mathrm{H}, \mathrm{m}), 8.01(1 \mathrm{H}, \mathrm{d}, J=7.0 \mathrm{~Hz}), 8.26(1 \mathrm{H}, \mathrm{s}) .{ }^{13} \mathrm{C}$ NMR $(75 \mathrm{MHz}$, $\left.\mathrm{CDCl}_{3}\right) \delta$, 43.5, 127.0, 127.1, 127.4, 127.5, 127.7, 127.8, 128.2, 128.3, 128.7, 130.6, 131.4, 131.9, 133.9, 138.1, 147.8, 167.7. HRMS m/z: $\mathrm{C}_{17} \mathrm{H}_{13} \mathrm{~N}_{2} \mathrm{OBr}$ requires $\left(\mathrm{M}^{+}\right)$, 340.0211. Found, 340.0203. N-(2-Cyanoquinolin-3-ylmethyl)benzamide (10). A mixture of the amide 9 (146 mg, $0.43 \mathrm{mmol}$ ), CuCN (154 mg, $1.72 \mathrm{mmol}), \mathrm{Pd}_{2}(\mathrm{dba})_{3}(15.6 \mathrm{mg}, 0.017 \mathrm{mmol})$, DPPF (38.3 mg, $0.069 \mathrm{mmol}$ ) and $\mathrm{Et}_{4} \mathrm{NCN}$ (67.2 $\mathrm{mg}, 0.43 \mathrm{mmol}$ ) in 1,4-dioxane (6.0 mL) was heated at reflux for $1 \mathrm{~h}$. The resultant mixture was diluted with EtOAc $(10 \mathrm{~mL})$ and the precipitates were filtered using Celite. The filtrate was washed with saturated aqueous $\mathrm{NaHCO}_{3}$ and saturated aqueous $\mathrm{NaCl}$, dried, and evaporated to leave the crude product, which was chromatographed. Elution with a 2:1 mixture of hexane-EtOAc afforded the amide 10 (120 mg, 97\%) as orange needles, m.p. $182{ }^{\circ} \mathrm{C}$. IR (KBr), 3262, 2226, $1639 \mathrm{~cm}^{-1} .{ }^{1} \mathrm{H}$ NMR (300 MHz, $\mathrm{CDCl}_{3}$ ), $\delta 4.97$ (2H, d, J=5.5 Hz), 7.05 (1H, br. s), 7.43 (1H, dt, J=7.5, 1.5 Hz), 7.44 (1H, dt, J= 7.5, 1.5 Hz), 7.54 (1H, ddd, J=8.0, 7.0, 1.5 Hz), 7.70 (1H, ddd, J=8.0, 7.0, 1.5 Hz), 7.78-7.85 (3H, m), 7.90 (1H, d, J=7.5 Hz), 8.15 (1H, d, J=8.0 $\mathrm{Hz}), 8.47(1 \mathrm{H}, \mathrm{s}) .{ }^{13} \mathrm{C}$ NMR (75 MHz, $\left.\mathrm{CDCl}_{3}\right), \delta$ 41.4, 116.6, 127.1, 128.0, 128.7, 128.8, 129.7, 129.8, 131.1, 132.1, 133.3, 133.5, 137.6, 147.5, 167.9. HRMS: $\mathrm{C}_{18} \mathrm{H}_{13} \mathrm{~N}_{3} \mathrm{O}$ requires $\mathrm{m} / \mathrm{z}$ : 287.1059. Found $\left(\mathrm{M}^{+}\right)$, 287.1071.

$N$-(2-Bromoquinolin-3-ylmethyl)-2-methoxybenzamide (12). To a stirred solution of the amine 7 (300 mg, $1.27 \mathrm{mmol}$ ) and 2-methoxybenzoic acid (11) (193 mg, $1.27 \mathrm{mmol}$ ) in $\mathrm{CH}_{2} \mathrm{Cl}_{2}(13 \mathrm{~mL})$ were added BOP (562 mg, $1.27 \mathrm{mmol})$ and $\mathrm{Et}_{3} \mathrm{~N}(0.35 \mathrm{~mL}, 2.54 \mathrm{mmol}$ ) at room temperature, and then the mixture was stirred at the same temperature for $30 \mathrm{~min}$. After removal of the solvent under reduced pressure, the crude product was chromatographed. Elution with a 2:1 mixture of hexane-EtOAc afforded the amide 12 (425 mg, 91\%) as white crystals, m.p. 153-155 ${ }^{\circ} \mathrm{C}$. IR $(\mathrm{KBr}) \mathrm{cm}^{-1}:$ 3395, 1654, 1241. ${ }^{1} \mathrm{H}$ NMR (300 MHz, $\mathrm{CDCl}_{3}$ ) $\delta: 4.00$ (3H, s), 4.85 (2H, d, J=6.0 Hz), 7.00 (1H, d, $J=7.5$ Hz), 7.09 (1H, ddd, $J=8.5,7.0,1.0$ Hz), 7.47 (1H, ddd, $J=9.0,7.5,1.5$ Hz), 7.56 (1H, ddd, $J=8.0,6.0,1.5 \mathrm{~Hz}), 7.71$ (1H, ddd, $J=9.0,7.0,1.5 \mathrm{~Hz}), 7.82$ (1H, d, $J=7.0 \mathrm{~Hz}), 8.02$ (1H, 
d, $J=7.5 \mathrm{~Hz}$ ), 8.21 (1H, dd, J=7.5, $1.5 \mathrm{~Hz}), 8.25$ (1H, s), 8.95(1H, br. s). MS m/z: $370\left(\mathrm{M}^{+}\right)$. Anal. $\mathrm{C}_{18} \mathrm{H}_{15} \mathrm{~N}_{2} \mathrm{OBr}$ requires C, 58.24; H, 4.07; N, 7.55. Found: C, 58.22; H, 4.31; N, 7.22\%.

$N$-(2-Cyanoquinolin-3-ylmethyl)-2-methoxybenzamide (13). A mixture of the amide 12 (100 mg, $0.27 \mathrm{mmol}$ ), CuCN (24.2 mg, $1.08 \mathrm{mmol}), \mathrm{Pd}_{2}(\mathrm{dba})_{3}(10.1 \mathrm{mg}, 0.011 \mathrm{mmol}), \mathrm{DPPF}$ (23.8 mg, $0.043 \mathrm{mmol}$ ) and $\mathrm{Et}_{4} \mathrm{NCN}$ (42.2 mg, $0.27 \mathrm{mmol}$ ) in 1,4-dioxane (3.0 mL) was refluxed for $1 \mathrm{~h}$. The resultant mixture was diluted with EtOAc $(5.0 \mathrm{~mL})$ and the precipitates were filtered off using Celite. The filtrate was washed with saturated aqueous $\mathrm{NaHCO}_{3}$ and saturated aqueous $\mathrm{NaCl}$, dried, and evaporated to lead to the crude product, which was chromatographed. Elution with a 2:1 mixture of hexane-EtOAc provided the amide 13 (72.0 mg, 84\%) as light yellow crystals, m.p. 195-196 ${ }^{\circ} \mathrm{C}$. IR (KBr) cm ${ }^{-1}$; 3380, 2228, 1640, 1247. ${ }^{1} \mathrm{H}$ NMR (300 MHz, $\left.\mathrm{CDCl}_{3}\right) \delta, 4.00$ (3H, s), 4.96 (2H, d, $J=6.0 \mathrm{~Hz}), 7.01$ (1H, d, $J=8.0 \mathrm{~Hz}$ ), 7.07 (1H, ddd, $J=8.0,7.5,1.5 \mathrm{~Hz}), 7.49$ (1H, dt, $J=$ 7.0, $1.0 \mathrm{~Hz}$ ), 7.67 (1H, ddd, J=9.0, 7.0, $1.5 \mathrm{~Hz}), 7.79$ (1H, ddd, $J=9.0,7.0,1.5 \mathrm{~Hz}), 7.89$ (1H, d, $J=7.0 \mathrm{~Hz}$ ), 8.13 (1H, d, $J=7.0 \mathrm{~Hz}), 8.18$ (1H, dd, $J=7.5,1.5 \mathrm{~Hz}), 8.46(1 \mathrm{H}, \mathrm{s}), 8.90(1 \mathrm{H}, \mathrm{br} \mathrm{s}) .{ }^{13} \mathrm{C}$ NMR (75 MHz, $\mathrm{CDCl}_{3}$ ) $\delta, 40.8,56.0,111.4,116.6,120.6,121.3,128.0,128.7,129.6,130.9$, 132.3, 133.4, 133.8, 133.9, 137.4, 147.3, 157.9, 165.9. HRMS m/z: $\mathrm{C}_{19} \mathrm{H}_{15} \mathrm{~N}_{3} \mathrm{O}_{2}$ requires 317.1164. Found, $317.1183\left(\mathrm{M}^{+}\right)$.

Luotonin A (4). A mixture of the amide 13 (12.5 mg, $0.06 \mathrm{mmol}), \mathrm{ZnCl}_{2}$ (16.4 mg, $0.12 \mathrm{mmol}$ ), TMSCl $(0.15 \mathrm{~mL}, 1.20 \mathrm{mmol})$ and $\mathrm{Et}_{3} \mathrm{~N}(0.17 \mathrm{~mL}, 1.20 \mathrm{mmol})$ in toluene $(3.0 \mathrm{~mL})$ was heated at $150{ }^{\circ} \mathrm{C}$ in a stainless sealed tube for $24 \mathrm{~h}$. After removal of the solvent under reduced pressure, saturated aqueous $\mathrm{NH}_{4} \mathrm{Cl}$ solution was added. The resulting mixture was extracted with EtOAc. The organic layer was washed with saturated aqueous $\mathrm{NaCl}$ solution, dried, and evaporated to leave the crude product, which was chromatographed. Elution with a 1:1 mixture of hexane-EtOAc afforded luotonin A (4) (5.2 mg, 46\%) as pale yellow needles after recrystallization from $\mathrm{CHCl}_{3}$, m.p. $281{ }^{\circ} \mathrm{C}$ [lit. ${ }^{7 \mathrm{c}}$ m.p. $\left.281-283{ }^{\circ} \mathrm{C}\left(\mathrm{CHCl}_{3}\right)\right]$. The spectroscopic data of our synthetic luotonin A are identical with those reported. ${ }^{6 a}$

\section{Acknowledgments}

This work is supported by a Grant-in-Aid (No. 14571994) from the Ministry of Education, Science, Sports and Culture, Japan. 


\section{References and Notes}

1. (a) Fringuelli, F.; Taticchi, A. The Diels-Alder Reaction: Selected Practical Methods; John Wiley \& Sons, Ltd: England, 2002. (b) Corey, E. J. Angew. Chem. Int. Ed. 2002, 41, 1651. (c) Nicolaou, K. C.; Snyder, S. A.; Montagnon, T.; Vassilikogiannakis, G. Angew. Chem. Int. Ed. 2002, 41, 1669.

2. (a) Boger, D. L.; Weinreb, S. M. Hetero Diels-Alder Methodology in Organic Synthesis, Academic Press, Inc: San Diego, 1987. (b) Behforouz, M.; Ahmadian, M. Tetrahedron, 2000, 56, 5259.

3. One of the authors has demonstrated that the intramolecular Diels-Alder reactions of dienynes, I, readily available from the benzaldehyde derivatives and ethyl 1-acetylcyclopentane-1-carboxylate, proceed to give the ABCD ring system II of Fredericamycin A (III). ${ }^{12}$

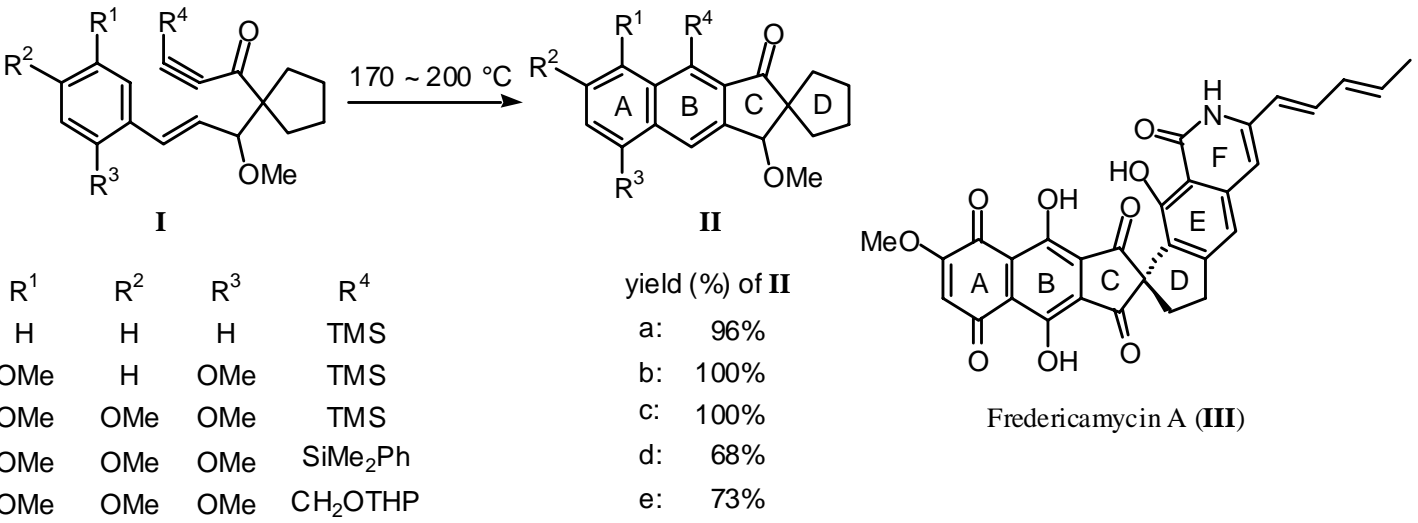

4. (a) Toyota, M.; Komori, C.; Ihara, M. J. Org. Chem. 2000, 65, 7110. (b) For the preliminary communication of this work, see ref. 7(e).

5. Dilthey, W.; Schommer, W.; Hoschen, W.; Dierichs, H. Chem. Ber. 1935, 68, 1159.

6. (a) Ma, Z.-Z.; Hano, Y.; Nomura, T.; Chen, Y.-J. Heterocycles 1997, 46, 541. (b) Ma, Z.-Z.; Hano, Y.; Nomura, T.; Chen, Y.-J. Heterocycles 1999, 51, 1883. (c) Ma, Z.-Z.; Hano, Y.; Nomura, T.; Chen, Y.-J. Phytochem. 2000, 53, 1075. 
7. (a) Wang, H. S; Ganesan, A. Tetrahedron Lett. 1998, 39, 9097. (b) Kelly, T. R.; Chamberland, S.; Silva, R. A. Tetrahedron Lett. 1999, 40, 2723. (c) Ma, Z.-Z.; Hano, Y.; Nomura, T.; Chen, Y.-J. Heterocycles 1999, 51, 1593. (d) Molina, P.; Tarraga, A.; Gonzalez-Tejero, A. Synthesis 2000, 1523. (e) Toyota, M.; Komori, C.; Ihara, M. Heterocycles 2002, 56, 101. (f) Osborne, D.; Stevenson, P. J. Tetrahedron Lett. 2002, 43, 5469. (g) Dallavalle, S.; Merlina, L. Tetrahedron Lett. 2002, 43, 1853. (h) Yadav, J. S.; Reddy, B. V. S. Tetrahedron Lett. 2002, 43, 1905.

8. Kekouar, K.; Ganisson, Y.; Leue, S.; Green, A. E. J. Org. Chem. 2000, 65, 5212.

9. Sakamoto, T.; Ohsawa, K. J. Chem. Soc., Perkin Trans. 1 1999, 2323.

10. Weinreb, S. M.; Staib, R. R. Tetrahedron 1982, 38, 3087.

11. Selected examples: (a) van Leusen, A. M.; Jagt, J. C. Tetrahedron Lett. 1970, 971. (b) Jagt, J. C.; van Leusen, A. M. J. Org. Chem. 1974, 39, 564.

12. Toyota, M.; Terashima, S. Tetrahedron Lett. 1989, 30, 829. 